\title{
Beyond Nanoparticles: The Role of Sub-nanosized Metal Species in Heterogeneous Catalysis
}

\author{
János Kiss ${ }^{1}$ · Ákos Kukovecz ${ }^{2,3} \cdot$ Zoltán Kónya ${ }^{1,2,3}$
}

Received: 28 November 2018 / Accepted: 26 February 2019 / Published online: 19 March 2019

(c) The Author(s) 2019

\begin{abstract}
Titanate nanostructures are of great interest for catalytic applications because their high surface area and cation exchange capacity create the possibility to achieve high metal dispersion. Ion exchange allows titanate nanostructures to incorporate metal adatoms in their framework. Consequently, the curved layers contain a large amount of defect sites, typically oxygen vacancies and $\mathrm{Ti}^{3+}$ centers, which can make them promising photocatalysts, because the defect sites can trap photoelectrons or holes extending the lifetime of the excited state. Due to the large amount of defects, titanate nanotubes (TNT) can stabilize sub-nanosized gold clusters, presumably in $\mathrm{Au}_{25}$ form. This perspective summarizes the previous results obtained in the photocatalytic transformation of methane in which the size of gold nanoclusters plays an important role. Photocatalytic measurements revealed that methane is active towards photo-oxidation. Methane transforms mainly into hydrogen and, to a lesser extent, to ethane and ethanol. Based on recent additional results, we stress here that gold clusters $\left(\mathrm{Au}_{25}\right)$ may be directly involved in the photo-induced reactions, namely in the direct activation of the methane/ $\mathrm{Au}_{25}{ }^{ }{ }^{+}$complex during irradiation. Another new finding is that gold nanoparticles supported on TNT exhibit high catalytic activity in $\mathrm{CO}_{2}$ hydrogenation. Our results revealed fundamental differences in the reaction schemes as the products of the two routes are CO (thermal process) and $\mathrm{CH}_{4}$ (photocatalytic route), indicating the importance of photogenerated electron-hole pairs in the reaction. The presence of gold nanoparticles on the surface has been found to have multiple roles. On the one hand, gold in nano and sub-nano sizes promotes the adsorption and scission of reactants, important for both types of reactions. On the other hand, the gold-support interface forms a rectifying Schottky contact that helps in the separation of photogenerated carriers, thus improving the utilization of electrons and holes in the reduction and oxidation steps, respectively. Furthermore, gold ions $\left(\mathrm{Au}^{+}\right.$), in the cationic sites of the titanate lattice promote the photocatalytic transformation of formate (which is one of the intermediates), thus advancing the reaction further towards the fully reduced product. The explored reaction schemes may pave the road towards novel catalytic materials that can solve challenges associated with the activation of $\mathrm{CH}_{4}$ and $\mathrm{CO}_{2}$ and thus contribute to green chemistry.
\end{abstract}

\section{Graphical Abstract}

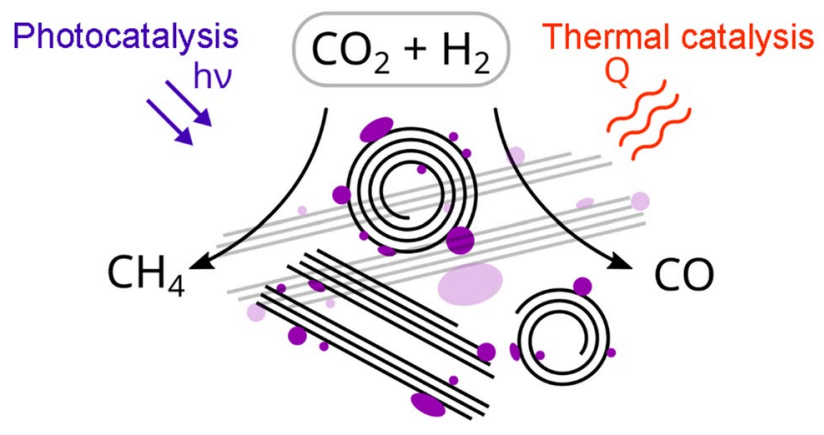

Keywords Catalysis $\cdot$ Nanotechnology $\cdot$ Elementary kinetics $\cdot$ Nanoclusters $\cdot$ Titanate nanostructures $\cdot$ Gold

Extended author information available on the last page of the article 


\section{Introduction}

The importance of the size and shape of metal nanoparticles supported on different oxides is in the focus of thermal- and photo-induced catalytic investigations today. Gold is usually an inert, poorly active catalyst. The majority of industrially important reactions cannot be catalyzed by gold, because even very reactive molecules like oxygen or hydrogen do not chemisorb on all gold surfaces [1]. However, earlier theoretical calculation has already beautifully explained why the flat surface of gold could be inert in hydrogen chemisorption [2]. Dissociative hydrogen adsorption on $\mathrm{Au} / \mathrm{Al}_{2} \mathrm{O}_{3}$ was experimentally demonstrated by in-situ X-ray absorption spectroscopy [3]. In this case, the high dissociative probability of hydrogen is related to the effect of the number of edges of Au clusters and the effect of strain [4].

Curiously, when dispersed as ultrafine particles over a metal oxide like titania, Au showed an outstanding effect for catalytic combustion, partial oxidation of hydrocarbons, hydrogenation of unsaturated hydrocarbons and reduction of nitrogen oxides [5]. Small Au clusters can promote the reaction between $\mathrm{CO}$ and oxygen at very low temperature $(40 \mathrm{~K})$ [6]. In CO oxidation, Au clusters invoke a marked increase in the reaction rate as the diameter of the Au clusters is decreased below $~ 3.5 \mathrm{~nm}$ [7]. Several possible explanations for this effect have been suggested. Some authors emphasize the special role of sites at the metal/support interface [8] and others point to the importance of coordinative unsaturation of the surface atoms [9]. Based on STM results, Goodman et al. ascribed the anomalous high activity of small clusters to quantumsize effects [10]. They found that gold particles form disclike structures on the oxide support and that the reactivity depends on the disc height. Recently scanning probe techniques have been used to determine the electronic and structural properties of supported Au particles as a function of the number of Au atoms in the particles [11, 12]. It was demonstrated how charge transfer between the support and the metal particle determines the shape of nanoparticles. The chemical potential versus particle size across the full size range between single isolated atom and bulk like limits is reported [13]. Very recently, metal catalysts for heterogeneous catalysis were surveyed from single atoms to nanoclusters and nanoparticles [14]. Metallic species of different size (single atom, nanoclusters, and nanoparticles) show different catalytic behavior in heterogeneous catalytic reactions. It was shown that the work function of Au species with different atomicity strongly depends on the particle size [15]. When a gold cluster contains less than 30 atoms, the work function varies significantly with the atomicity. However, as the atomicity increases to above
70 atoms $(>1.5 \mathrm{~nm})$, the work function remains constant and then slowly increases with the particle size. The sizedependent electronic structure is more significant when the $\mathrm{Au}$ nanoclusters consist of less than 40 atoms [16]. The situation is well-represented in Fig. 1.

As shown in Fig. 1, the frontier orbital panels of $\mathrm{Au}_{\mathrm{n}}$ atoms $(n \leq 7)$ consist of several lobes localized on the $\mathrm{Au}$ atoms with unsaturated coordination environment. When the atomicity increases above 8 , the geometric structure of the $\mathrm{Au}$ nanocluster will change from planar to 3D [17]. When the atomicity of metal particles increases to $>40$ (with particle size $>1 \mathrm{~nm}$ ), the bandgap between HOMO and LUMO becomes smaller than those in subnanometric metal clusters. For larger metal nanoparticles ( $>2 \mathrm{~nm}$ ), a continuous band structure will form.

The size of nanoparticles also plays an important role in photo- and external energy-mediated surface chemistry. Elucidating molecular energy transfer processes at metal surfaces is challenging because the energy dissipates within femtoseconds or picoseconds by non-adiabatic electron excitation (i.e., e-h pairs). Generally, depositing noble metals onto a semiconductor surface can appreciably suppress the rate of exciton recombination as the clusters serve as electron sinks. Au nanoparticles have often been coupled to $\mathrm{TiO}_{2}$ support to exploit their localized surface plasmonic resonance (LSPR) property in photocatalysis [18-20]. LSPR is a collective free electron charge oscillation in metallic nanoparticles excited by light [21]. This phenomenon usually occurs in nanoparticles larger than 3-5 nm, and it strongly depends on particle size, shape and local dielectric environment [22]. In perspective, hot electrons and surface plasmons can be used to change the catalytic activity using metal-oxide nanocatalysts [23-25]. Besides, it is worth investigating the catalytic activity of sub-nanosized metal particles (below 2-3 nm) and metal ions in theoretically and technologically important catalytic reactions. When the photogenerated electrons are produced in the semiconductor, they will probably be transferred to the metal particles through a Schottky barrier [19]. The charge transfer rates between oxide nanoparticles and Au clusters may depend on cluster size. It is well-demonstrated in the case of $\mathrm{ZnO} / \mathrm{Au}_{\mathrm{n}}$ system displayed in Fig. 2 [26]. Ultrafast spectroscopic measurements showed that when the Au particle size increases from ca. $<2-3 \mathrm{~nm}\left(\mathrm{Au}_{25}\right)$ to ca. $<3.5 \mathrm{~nm}$ $\left(\mathrm{Au}_{807}\right)$, the charge-transfer rate also increases, leading to higher photocatalytic activity in the case of thionine degradation [26].

In this Perspective we discuss the role of sub-nanosize particles in thermal- and photo-induced catalytic reactions. We consider that small clusters $(<2-3 \mathrm{~nm})$ loose their bulklike electronic properties (e.g. no Fermi level); for example, they no longer support the plasmonic excitation characteristic of relatively large metal nanocrystals $(3-50 \mathrm{~nm})$. Such 


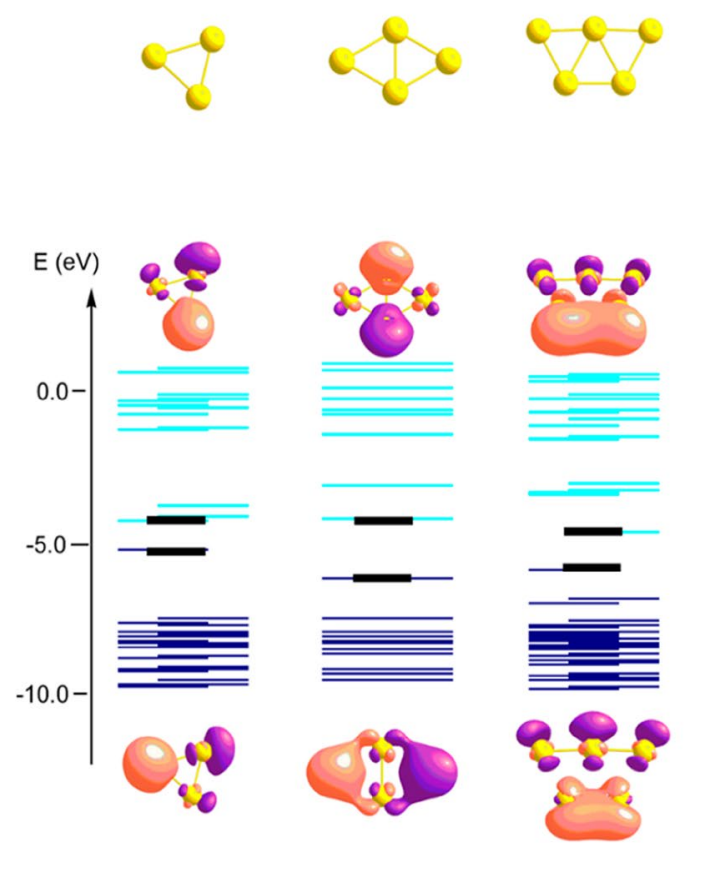

Fig. 1 Electronic structures of Au clusters according to theoretical calculations. Optimized structure (top) and calculated isosurfaces of the lowest unoccupied molecular orbital (LUMO center) and highest occupied molecular orbital (HOMO, bottom) of $\mathrm{Au}_{3}, \mathrm{Au}_{5}, \mathrm{Au}_{6}$,
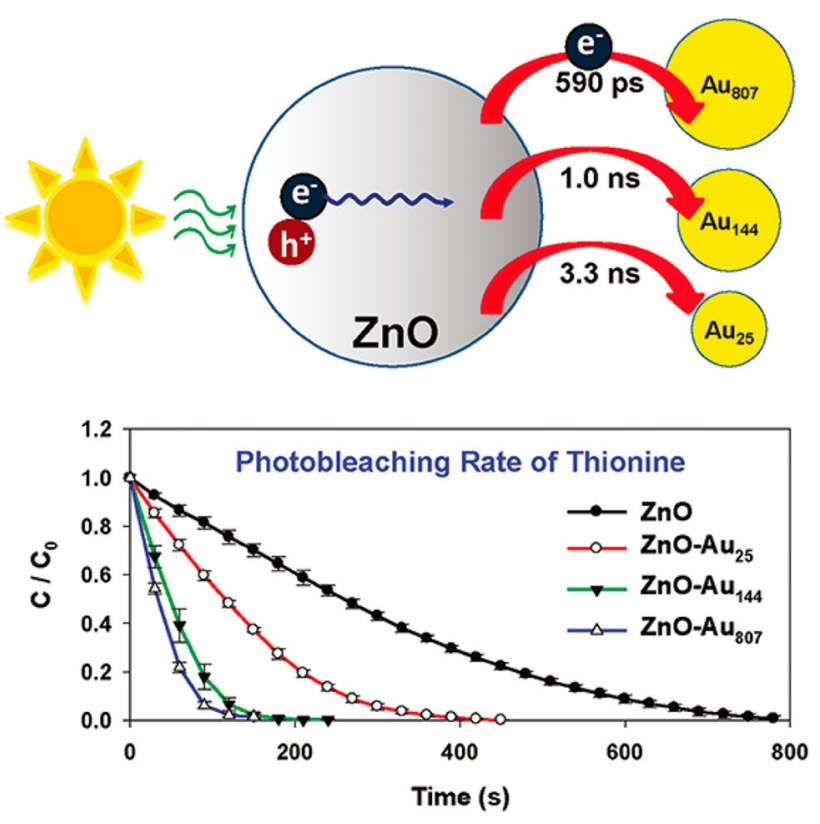

Fig. 2 Schematic illustration of charge transfer between $\mathrm{ZnO}$ nanoparticles and Au particles with different size. The kinetic curve of photocatalytic degradation of thionine (a model dye molecule). Reprinted with permission from Ref. [26]. Copyright 2011 American Chemical Society
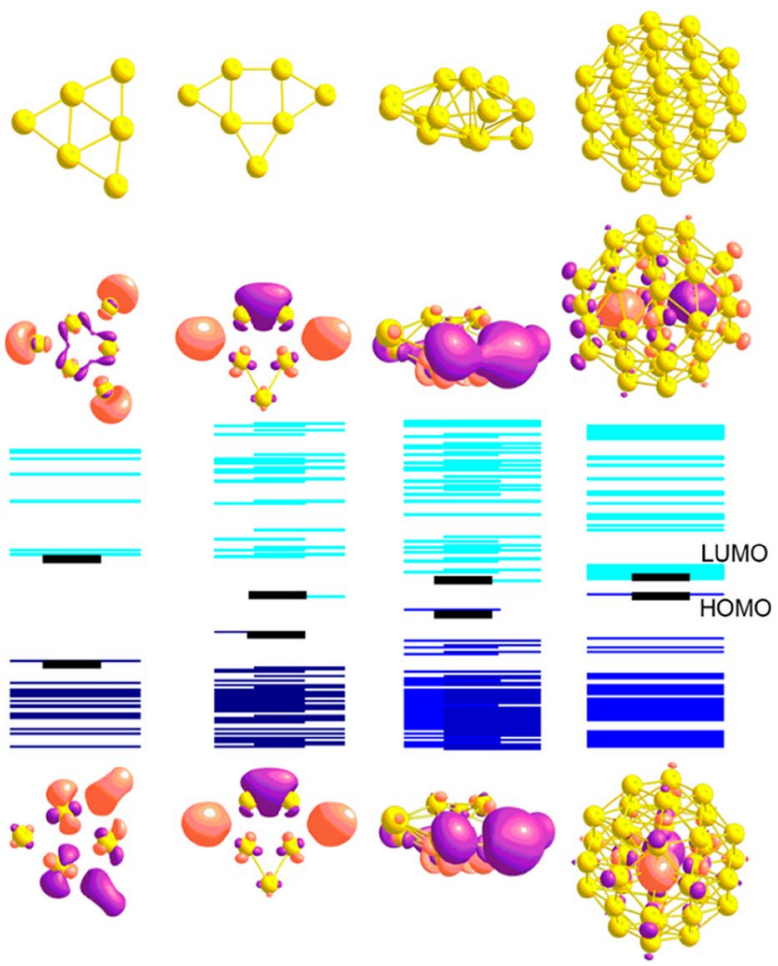

$\mathrm{Au}_{7}, \mathrm{Au}_{13}$, and $\mathrm{Au}_{38}$ clusters, together with the molecular orbital level in blue. Reprinted with permission from Ref. [16]. Copyright 2018 American Chemical Society

"molecular-like" clusters can be stabilized on several oxides. Besides small clusters, single atoms or ions can be stabilized by oxides (mainly by titanates) as well. In this study, we focus mostly on "molecular-like" gold clusters $\left(\mathrm{Au}_{\mathrm{n}}\right.$; $\mathrm{n} \leq 25)$ and single gold atoms or gold ions $\left(\mathrm{Au}^{\mathrm{n}+} ; \mathrm{n} \geq 1\right)$, which could contribute to developing further a progressive direction in heterogeneous catalysis.

\section{Catalysis on Gold Nanoclusters (AuNCs) Deposited on Metal Oxides: A Short Review}

Gold nanoclusters (AuNCs) formed on oxide supports have been found to be catalytically active depending on the number of atoms forming the clusters [27, 28]. The catalytic properties depend on the $\mathrm{Au}-\mathrm{Au}$ distance, the coordination number and the electronic structure of the cluster [29, 30]. Scanning probe techniques were used to determine the electronic and structural properties of supported particles as a function of the number of $\mathrm{Au}$ atoms in the particle on $\mathrm{MgO}$ and other doped oxide materials. It was demonstrated how charge transfer between the support and the particles determines the shape of nanoparticles [12, 31]. The oxidation of $\mathrm{CO}$ was investigated on $\mathrm{Au}_{8}$ clusters on $\mathrm{MgO}[32,33]$. 
It was found that gold octamers bound to oxygen vacancies ( $\mathrm{F}$ centers) of the magnesia surface can oxidize $\mathrm{CO}$ into $\mathrm{CO}_{2}$ at as low as $140 \mathrm{~K}$. The same clusters bound to oxygen vacancy-free $\mathrm{MgO}$ are catalytically inactive in $\mathrm{CO}$ combustion. Ab initio simulations, in juxtaposition with laboratory experiments, led to the conclusion that the key to low-temperature gold catalysis in $\mathrm{CO}$ oxidation is the binding of $\mathrm{O}_{2}$ and $\mathrm{CO}$ to the supported gold nanoclusters, which activates the $\mathrm{O}-\mathrm{O}$ bond into a peroxo-like adsorbate state $[32,34] . \mathrm{Au}_{9}$ clusters were deposited via ligand-protected decomposition onto titania nanosheets and characterized by high-resolution HAADF-STEM, XPS and DFT calculations. The Au core of all clusters measured approximately $5 \AA$ in diameter. The mean interatomic distance was $2.51 \pm 0.17 \AA$. The XPS peak position of $\mathrm{Au}_{9}$ was shifted by $0.8 \mathrm{eV}$ above that of the bulk Au position $(84.0 \mathrm{eV})$. This shift was attributed to the cluster size induced final state effect [30].

Thiol-stabilized gold nanoclusters have attracted significant research interest not only in catalysis [35-38], but also in biomedicine [39] and chemical sensors [40]. X-ray crystallographic analysis revealed that the $\mathrm{Au}_{25}$ cluster is based on a centered icosahedral $\mathrm{Au}_{13}$ core capped by an exterior shell composed of the remaining twelve Au atoms, and the whole cluster is encapsulated by eighteen thiolate ligands $[41,42]$. Because of strong quantum size effects, the $\mathrm{Au}_{25}$ cluster shows multiple molecular-like transitions in its optical absorption spectrum; well-defined bands are observed in the UV-Vis spectrum at 1.8, 2.75, and $3.1 \mathrm{eV}$ [42]. For thiol-stabilized $\mathrm{Au}_{38}$ clusters different bands were observed at 1.64 and $2.0 \mathrm{eV}$ [38].

Supported and size-controlled Au clusters can be prepared with the thiol-ligated solution-based method, providing a new approach to the synthesis of such catalysts. Recently $\mathrm{Au}_{25}(\mathrm{SR})_{18}\left(\mathrm{SR}=-\mathrm{SCH}_{2} \mathrm{CH}_{2} \mathrm{Ph}\right)$ has been successfully deposited on $\mathrm{CeO}_{2}$ rods [43], as demonstrated in Fig. 3. A HAADF-STEM image of the as-synthesized $\mathrm{Au}_{25}(\mathrm{SR})_{18} / \mathrm{CeO}_{2}$ rod catalysts with the UV-Vis spectrum and MS pattern of the as-synthesized $\mathrm{Au}_{25}(\mathrm{SR})_{18}$ nanoclusters are displayed. This gold cluster on ceria system was explored in $\mathrm{CO}$ oxidation as a probe reaction. Kinetic tests, in situ IR and X-ray absorption spectroscopy, and density functional theory (DFT) were employed to characterize the reaction. The intact $\mathrm{Au}_{25}(\mathrm{SR})_{18}$ on the $\mathrm{CeO}_{2}$ rod was unable to adsorb $\mathrm{CO}$. Only when the thiolate ligands are removed is the activation started, and then $\mathrm{CO}$ oxidation occurs below $423 \mathrm{~K}$. Cationic Au sites (charged between 0 and +1 ) are found to play a major role in low-temperature $\mathrm{CO}$ oxidation. The particle size of $\mathrm{Au}(1-1.5 \mathrm{~nm})$ was the same in the unsupported and the $\mathrm{CeO}_{2}$-supported case. A strong interaction must exist between Au nanoclusters and $\mathrm{CeO}_{2}$ rods to prevent agglomeration at high temperatures such as $673 \mathrm{~K}$.

$\mathrm{TiO}_{2}$ supported $\mathrm{Au}_{38}(\mathrm{SR})_{24}$ nanoclusters did not show high activity for $\mathrm{CO}$ oxidation unless the thiolate ligands were removed. Treatment with $\mathrm{H}_{2} / \mathrm{He}$ at $673 \mathrm{~K}$ removed most of sulfur-containing ligand and also increased the average $\mathrm{Au}$ size to $3.9 \mathrm{~nm}$. The obtained $0.7 \% \mathrm{Au} / \mathrm{TiO}_{2}$ catalysts showed the expected Arrhenius behavior, with apparent activation energy of $31.2 \mathrm{~kJ} / \mathrm{mol}$ for the $\mathrm{CO}+\mathrm{O}_{2}$ reaction. However, the turnover frequency of $0.7 \% \mathrm{Au}_{38} /$ $\mathrm{TiO}_{2}$ was lower than that of catalysts prepared by conventional methods [38].
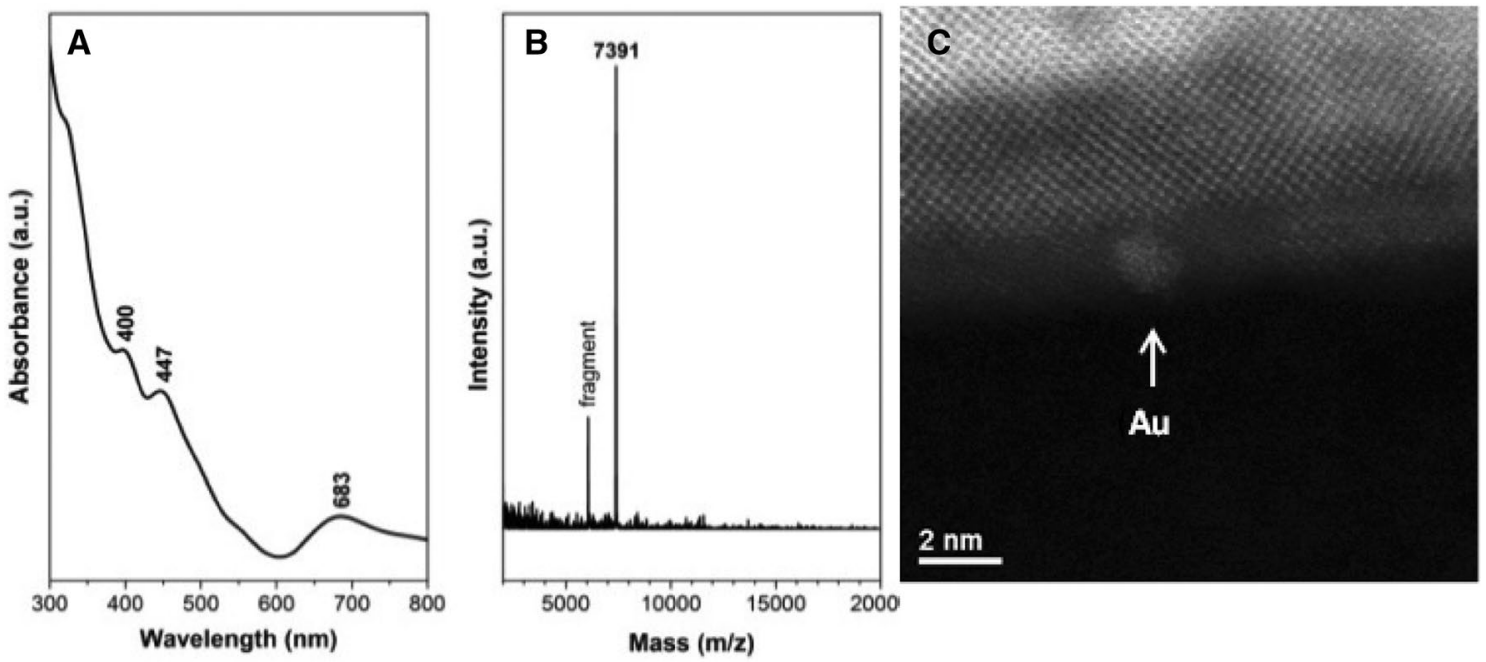

Fig. 3 a UV-Vis spectrum and b MS pattern of the as-synthesized $\mathrm{Au}_{25}(\mathrm{SR})_{18}$ nanoclusters, $\mathbf{c}$ HAADF-STEM image of the as-synthesized $\mathrm{Au}_{25}(\mathrm{SR})_{18} / \mathrm{CeO}_{2}$ rod catalysts. The scale bar represents $2 \mathrm{~nm}$.
Adapted with permission from Ref. [43]. Copyright 2014 American Chemical Society 


\section{Catalysis in the Presence of Au Cluster $\left(\mathrm{Au}_{25}\right)$ and $\mathrm{Au}^{+}$Ion on Titanate Nanostructures}

\subsection{Formation and Characterization of $\mathrm{Au}_{25}$ Cluster and $\mathrm{Au}^{+}$Ion on Titanate Nanostructures}

Titanates are salts of polytitanic acid that can be synthesized as nanostructures in a great variety concerning crystallinity, morphology, size, metal content and surface chemistry. Recently, the structure and properties of titanate nanotubes (TNTs) were widely characterized by several material and surface science tools [44-51]. They are open-ended hollow

Table 1 Characteristic data of the different catalysts

\begin{tabular}{|c|c|c|c|c|}
\hline Catalyst & $\begin{array}{l}\text { Nominal } \\
\text { gold content } \\
\text { (wt } \%)\end{array}$ & $w_{A u}(\mathrm{wt} \%)$ & $\begin{array}{l}\text { BET surface } \\
\text { area }\left(\mathrm{m}^{2} / \mathrm{g}\right)\end{array}$ & $\begin{array}{l}\text { Mean gold } \\
\text { particle } \\
\text { diameter } \\
(\mathrm{nm})\end{array}$ \\
\hline $\mathrm{TiO}_{2}$ & - & - & $50 \pm 5$ & - \\
\hline TNT & - & - & $330 \pm 30$ & - \\
\hline $\mathrm{Au} / \mathrm{TiO}_{2}(\mathrm{~A})$ & 1 & $1 \pm 0.1$ & $45 \pm 5$ & $8.6 \pm 1.5$ \\
\hline $\mathrm{Au} / \mathrm{TNT}(\mathrm{A})$ & 1 & $1 \pm 0.1$ & $310 \pm 30$ & $9.4 \pm 2.9$ \\
\hline $\mathrm{Au} / \mathrm{TiO}_{2}(\mathrm{~B})$ & 1 & $0.87 \pm 0.09$ & $45 \pm 5$ & $3.9 \pm 1.5$ \\
\hline $\mathrm{Au} / \mathrm{TNT}(\mathrm{B})$ & 1 & $0.3-0.9$ & $310 \pm 30$ & $3.1 \pm 0.9$ \\
\hline
\end{tabular}

The catalysts denoted with (A) were synthesized by incipient wetness impregnating method followed by reducing with $\mathrm{H}_{2}$ at $473-573 \mathrm{~K}$. (B) stands for the deposition-precipitation method with $\mathrm{NaBH}_{4}$ reducing agent. The gold content $\left(\mathrm{w}_{\mathrm{Au}}\right)$ was measured by inductively coupled plasma mass spectrometry cylinders measuring up to $200 \mathrm{~nm}$ in length and $15 \mathrm{~nm}$ in outer diameter $[44,45]$. They have numerous advantageous properties that play important roles in several catalytic reactions. It is well known that the larger amount of defect sites $\left(\mathrm{Ti}^{3+}\right.$ and oxygen vacancy) compared to pristine $\mathrm{TiO}_{2}$ produces more donor levels, thus making titanates generally more active. Moreover, the high surface area and cation exchange capacity of titanate nanostructures provide the possibility of achieving high metal dispersion over them. Ion exchange allows titanate nanostructures to incorporate metal adatoms in their framework, which may create another type of active center besides metal clusters [45, 46]. This allows an atomic-scale distribution of metal cations in the titanate lattice.

The size of gold particles can be influenced by the preparation method [48, 51]. In Table 1. we summarize important data obtained for two different preparation methods, namely impregnation followed by reducing with $\mathrm{H}_{2}$ at $473-523 \mathrm{~K}$ (method A), and deposition-precipitation with $\mathrm{NaBH}_{4}$ as the reducing agent (method $\mathrm{B})$.

Smaller cluster sizes can be achieved by reducing with $\mathrm{NaBH}_{4}$. A characteristic particle size distribution was calculated and plotted in Fig. 4. The size of the TEM-identified Au nanoparticles is in the 1-6 nm range. The average particle size is $3.1 \pm 0.9 \mathrm{~nm}$, and the most abundant size is $2.5-3.0 \mathrm{~nm}$.

In our previous works [47-50] we demonstrated that the XP spectra reflect to the formation of $\mathrm{Au}^{+}$(gold in ion-exchange position) and small clusters. In the present perspective we attempt to separate the $\mathrm{Au}^{+}$and gold clusters $(<2-3 \mathrm{~nm})$ and estimate their quantity obtained using the two preparation methods. Symmetric Au $4 \mathrm{f}_{5 / 2}$ and $4 \mathrm{f}_{7 / 2}$
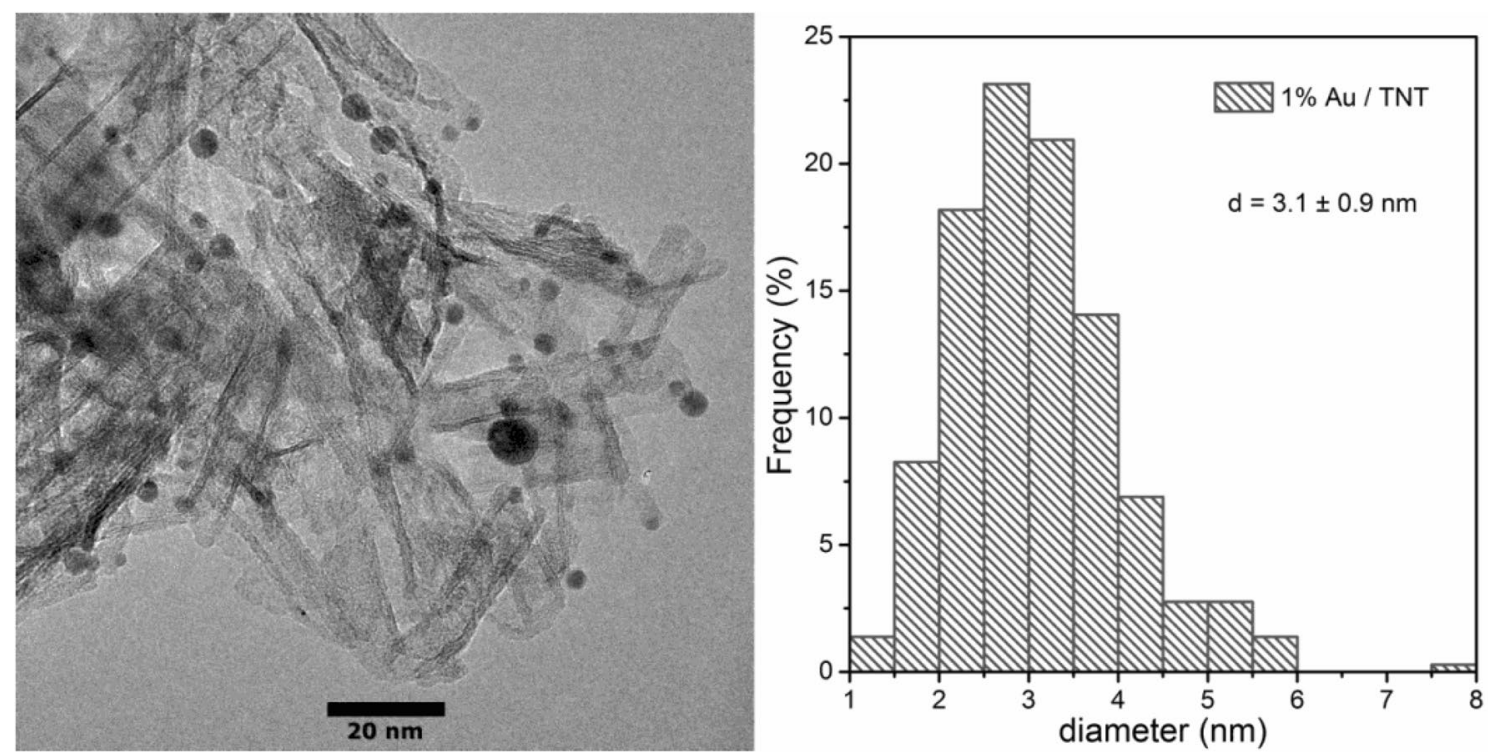

Fig. 4 TEM image (left) and corresponding particle size distribution (right) of Au particles in a Au/TNT (B) system. Reproduced from Ref. [51] 
emissions were observed at 87.7 and $84.0 \mathrm{eV}$, which corresponds to $\mathrm{Au}^{0}$. An additional peak with significant intensity appeared at $85.9 \mathrm{eV}$ (Fig. 5). A very tiny emission could be resolved after deconvolution at $84.7 \mathrm{eV}\left(\mathrm{Au} 4 \mathrm{f}_{7 / 2}\right)$ after reduction with $\mathrm{NaBH}_{4}$ (Fig. 5a). These features were also identified in the $\mathrm{Au}_{5 / 2}$ component. The spectrum of a clean Au film prepared on glass is also shown (Fig. 5c).

The peak at $85.9 \mathrm{eV}$ can be assigned to $\mathrm{Au}^{+}$ions in the ion exchange positions of TNT [45, 47, 48]. Core level shifts due to low particle size may also contribute to the peak at $\sim 84.7 \mathrm{eV}$ that cannot be resolved in Fig. 5b, where the particle size is $9.4 \pm 2.9 \mathrm{~nm}$. The highest $\mathrm{Au}^{+}$ $\left(\mathrm{Au}^{\mathrm{n}+}\right)$ ion concentration was reached when the reduction of gold was carried out with $\mathrm{NaBH}_{4}$ at room temperature. A higher binding energy peak $(85.9 \mathrm{eV})$ with much smaller intensity was detected by XPS when the reduction was done with hydrogen at $473-573 \mathrm{~K}$ (Fig. 5b). Using this method, the resulting Au particles have 8-10 nm size [45, 47-49]. For comparison we mention here that on $\mathrm{TiO}_{2}$, the size of gold nanoparticles depends also on the preparation method. According to XPS analysis, the $\mathrm{Au} 4 \mathrm{f}_{7 / 2}$ peak appeared at $84.0 \mathrm{eV}$. Only a very small high energy side shoulder (or none at all) attributable to ions or any appreciable amount of gold clusters was observed [52]. Thus it is evident that in the $\mathrm{TiO}_{2}$ case, there is no gold in ion exchange positions.

In order to get more information about the XPS position of small amounts of gold clusters we previously studied the gold deposition on stoichiometric and reduced $\mathrm{TiO}_{2}(110)$ model systems [50]. The Au $4 \mathrm{f}_{7 / 2}$ peak positions were measured as a function of Au coverage.
The peak appeared at $84.3 \mathrm{eV}$ at very low coverage $(0.04$ ML) on the stoichiometric $\mathrm{TiO}_{2}(110)$ surface. The position of this emission shifted slightly to lower binding energy with increasing coverage. Above $1 \mathrm{ML}$ coverage it was located at $84.0 \mathrm{eV}$, which corresponds to the bulk position. On reduced $\mathrm{TiO}_{2}(110)$ the binding energy shift from submonolayer to monolayer is larger $(>0.6 \mathrm{eV} ; 84.6 \mathrm{eV})$ than that on the stoichiometric surface. The deposited Au forms smaller crystallites in higher density on the thermally reduced surface (higher number of $\mathrm{Ti}^{3+}$ sites) relative to the stoichiometric substrate (Fig. 6).

On $\mathrm{Au}_{9} / \mathrm{TiO}_{2}$ the binding energy for $\mathrm{Au}_{9}$ was $84.8 \mathrm{eV}$. This $0.8 \mathrm{eV}$ upward shift (compared to bulk gold position $(84.0 \mathrm{eV}))$ was attributed to the final state effect due to small clusters $[26,29]$. These experiments show that the cluster size effect causes smaller binding energy shift than the $\mathrm{Au}^{+}$in ion exchange position on TNT. Based on these data we can separate the $\mathrm{Au}^{+}$position $(85.9 \mathrm{eV})$ and that of small clusters $(\sim 84.7 \mathrm{eV})$. This latter weak binding energy peak could not be resolved when the reduction occurred with hydrogen at $473-573 \mathrm{~K}$ and the average size was $9.4 \pm 2.9 \mathrm{~nm}$ (Fig. 2b). It appears that the intensity of the measured highest binding energy peak $(85.9 \mathrm{eV})$ on TNT in XPS is roughly proportional to the amount of $\mathrm{Au}^{+}$incorporated in the titanate framework.

Pure TNT showed a strong absorption at $3.59 \mathrm{eV}(351 \mathrm{~nm}$ wavelength) in UV-Vis experiments. The bandgap energy calculated from the Tauc plot was $3.07 \mathrm{eV}$ (Fig. 7). The bandgap of $1 \mathrm{wt} \% \mathrm{Au} / \mathrm{TNT}$ was slightly smaller $(3.03 \mathrm{eV})$, but no significant further changes were observed at $2.5 \mathrm{wt} \%$ $\mathrm{Au}$ content. The spectrum of Au/TNT shows a strong
Fig. 5 XP-spectra from the gold $4 \mathrm{f}$ region taken on titanate nanotubes after reduction with $\mathrm{NaBH}_{4}(\mathbf{a})$, spectrum obtained after reduction with hydrogen at $473-573 \mathrm{~K}(\mathbf{b})$, and on a clean Au film prepared on a glass plate (c)

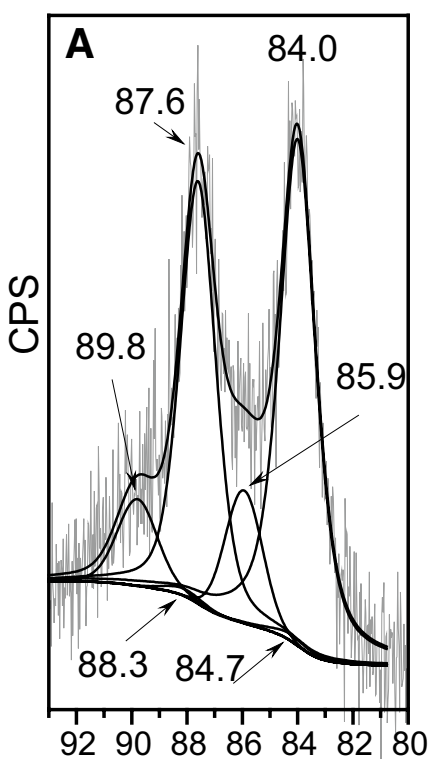

\section{Au $4 f$}

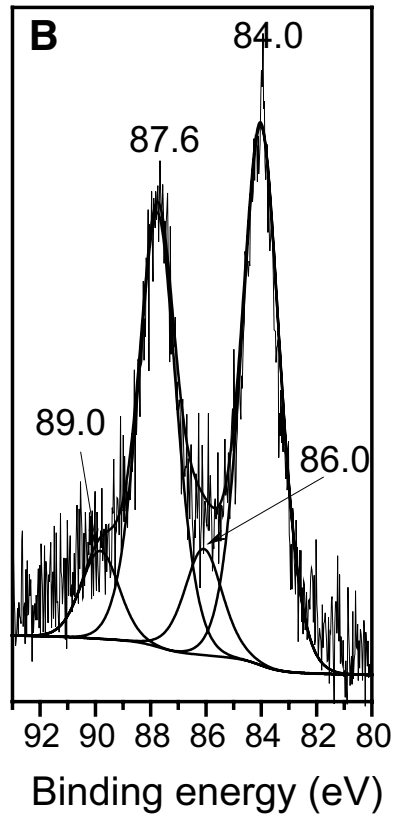

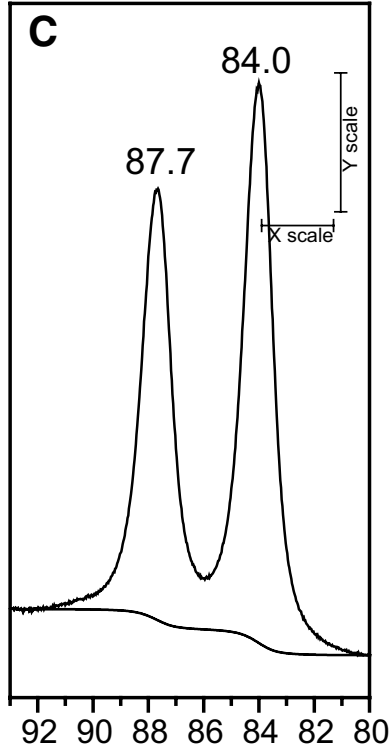


Fig. 6 Characteristic XP spectra of the samples: the $\mathrm{Ti} 2 \mathrm{p}$ region of the nearly stoichiometric $\mathrm{TiO}_{2}(110)$ surface and after $\mathrm{Ne}^{+}$bombardment (a); the $\mathrm{Au}$ $4 \mathrm{f}$ region collected after the evaporation of an increasing amount of $\mathrm{Au}$ at $300 \mathrm{~K}$ on a nearly stoichiometric $\mathrm{TiO}_{2}(110)$ (b) and on the $\mathrm{Ne}^{+}$sputtered titania surface (c). d Depicts the $\mathrm{Au} 4 \mathrm{f} 7 / 2$ peak positions as a function of $\mathrm{Au}$ coverage on the stoichiometric and on the sputtered $\mathrm{TiO}_{2}(110)$. Reproduced from Ref. [50], licensed under CC BY 4.0
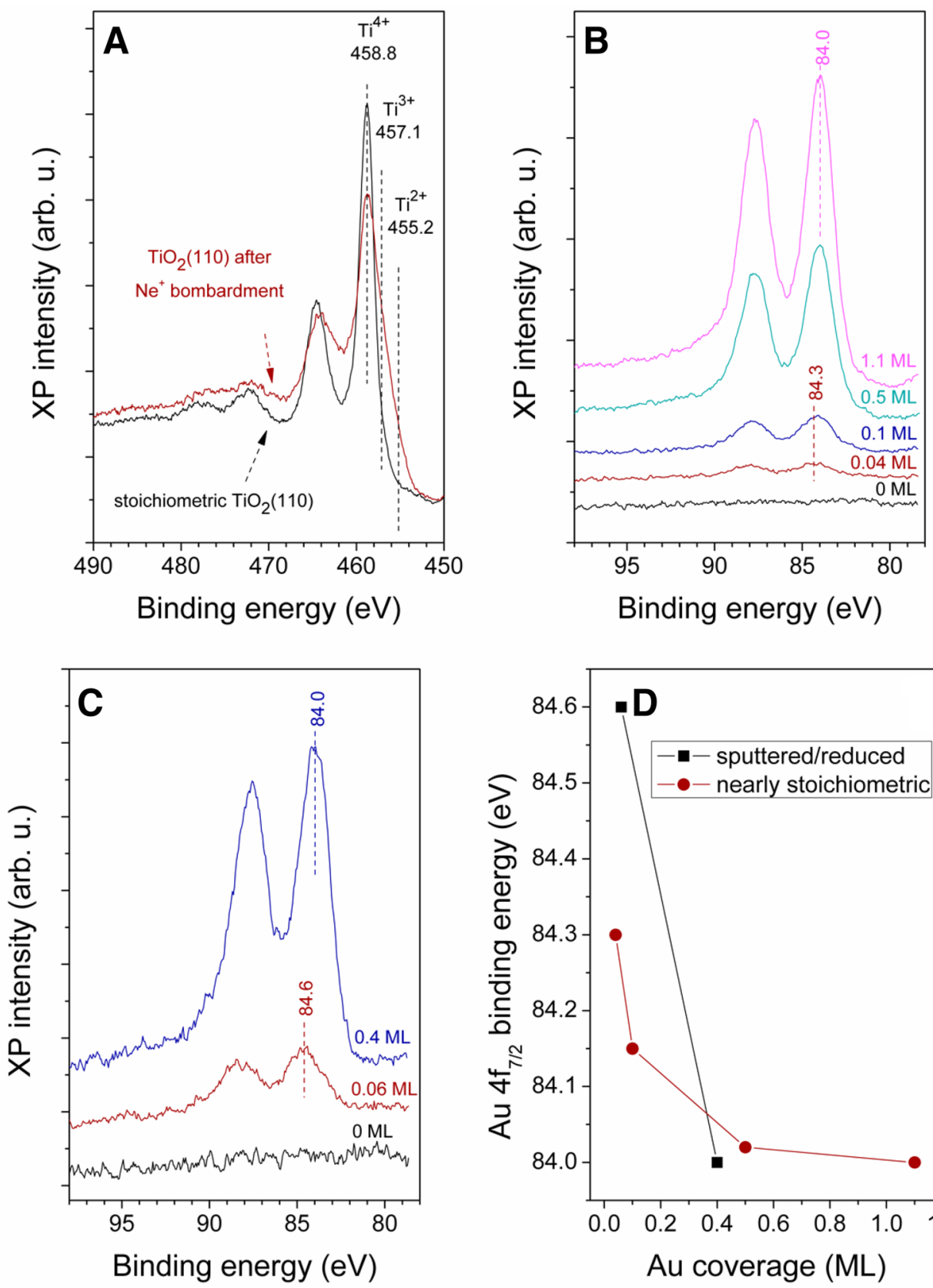

absorption band at $2.31 \mathrm{eV}(534 \mathrm{~nm})$. This is the characteristic absorption of the surface plasmon of gold nanoparticles $(\mathrm{d}>3 \mathrm{~nm})$ and arises as a result of the collective modes of oscillation of the free conduction band electrons induced by an interacting electromagnetic field [18-21]. Interestingly, the spectrum also shows some unresolved peaks, mostly at higher energies. After deconvolution we can identify four absorptions at $1.60 \mathrm{eV}(774 \mathrm{~nm}),(2.68 \mathrm{eV}(426 \mathrm{~nm}))$, $2.93 \mathrm{eV}(423 \mathrm{~nm})$, and $3.19 \mathrm{eV}(388 \mathrm{~nm})$, due to small clusters (Fig. 7).

It has been demonstrated above by XPS and HRTEM measurements that our titanate nanotube samples contain gold in very small sizes $(\mathrm{d}<3 \mathrm{~nm})$ (Figs. 4, 5) as well.
It should be emphasized that small gold nanoparticles $(\mathrm{d}<3 \mathrm{~nm})$ lose their bulk-like electronic properties; for example, they no longer show the plasmon excitation characteristics of relatively large gold nanocrystals. Multiple molecular-like transitions of a thiol-protected $\mathrm{Au}_{25}$ cluster were observed as at least three well-defined bands at 1.8, 2.75, and $3.1 \mathrm{eV}$ by UV-Vis spectroscopy [42]. A similar $\mathrm{Au}_{25}$ cluster was identified on $\mathrm{CeO}_{2}$ rod catalyst [43]. Based on these similarities in the UV-Vis spectra we assume that such molecular-like clusters may also exist on titanate structures. The common property of $\mathrm{CeO}_{2}$ rods and TNTs is that they both contain huge amounts of defects necessary for the stabilization of $\mathrm{Au}_{25}$ clusters. Since we cannot rule out the 

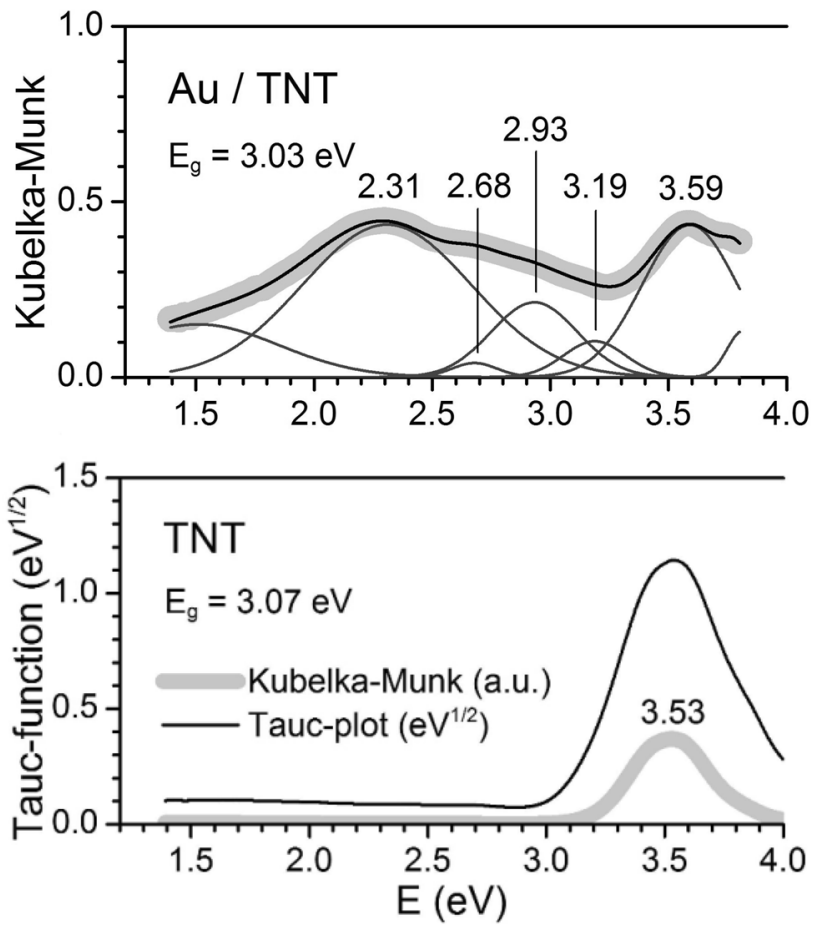

Fig. 7 DR-UV-VIS spectra with the calculated bandgap energies of two different samples. The original spectra are shown by the thick, grey curves. Bandgap energies were calculated from fitted Gaussian functions with Tauc's method in all cases. (Partially reproduced from Ref. [48])

possibility that the stabilized $\mathrm{Au}_{25}$ cluster has a partial positive charge, these species may contribute to the higher binding energy tailing of $\mathrm{Au} 4 \mathrm{f}_{7 / 2}$. For comparison: the removal of thiolate ligands from the $\mathrm{Au}_{25}(\mathrm{SR})_{18} / \mathrm{CeO}_{2}$ rod catalyst resulted in three types of $\mathrm{Au}$ sites: $\mathrm{Au}^{\mathrm{n}+}(0<\mathrm{n}<1), \mathrm{Au}^{+}$, $\mathrm{Au}^{\mathrm{n}-}(0<\mathrm{n}<1)$ [43]. In our case, no negatively charged $\mathrm{Au}$ (indicated by a binding energy peak below the metallic $\mathrm{Au}$ position in the XP spectrum) was observed on TNT (Fig. 5).

\subsection{2 Possible Role of $\mathrm{Au}_{25} / \mathrm{TNT}$ and $\mathrm{Au}^{+} / \mathrm{TNT}$ in the Photocatalytic Transformation of $\mathrm{CH}_{4}$}

Photocatalytic reactions were carried out in a flow-type photoreactor described in detail previously [48]. An immersion-type mercury-arc lamp placed in the center of reactor was used for irradiation. The reaction products were analyzed by a Hiden HPR-70 gas analysis system. Photocatalytic measurements revealed that methane is active towards photo-oxidation: it transforms mainly to hydrogen and, to a lesser extent, to ethane and methanol. We summarize here the most important photocatalytic data obtained on Au/TNT that contains small Au clusters and $\mathrm{Au}^{+}$, and they are compared to that measured on $\mathrm{Au} / \mathrm{TiO}_{2}$ (which does not contain small clusters or gold cations) (Table 2). The table shows the average and maximal formation rates of the identified products and the methane conversion values. Au/TNT catalysts exhibited much higher activity in methane conversion than pristine nanotubes. The $\mathrm{Au} /$ $\mathrm{TiO}_{2}$ showed considerably smaller activity than the nanotube supported variant [48].

In this section we discuss the main photocatalytic steps with emphasis of the role of small clusters and gold ions $\left(\mathrm{Au}^{+}\right)$in certain steps. On Au/TNT no activity loss was observed. It was already established that TNT contain a large amount of structural (lattice) $\mathrm{H}_{2} \mathrm{O}$ [45]. When explaining the outstanding activity of Au/TNT, one should take into account that water could be a plausible reaction partner, which provides the oxygen reacting with the methyl radical.

It is generally accepted that electron-hole pairs are generated on metal (gold) promoted TNT upon the absorption of UV light [22].

$T N T \stackrel{h v}{\rightarrow} T N T\left(e^{-}, h^{+}\right)$

$\operatorname{TNT}\left(e^{-}, h^{+}\right) \rightleftharpoons \operatorname{TNT}\left(e^{-}\right)+\operatorname{TNT}\left(h^{+}\right)$

After the dissociation of the exciton described by Eq. 2, the electron and the hole migrate to energetically favorable positions. Electrons have a higher possibility to be found on the metal particles (Eq. 3) due to Fermi-level equilibration between the metal and the oxide [19].

$T N T\left(e^{-}\right) \rightleftharpoons M\left(e^{-}\right)$

The charge separation reaches an equilibrium that is controlled by diffusion and drift currents and depends strongly on the rates of charge carrier generation and recombination.

Surface water molecules can catch the hole and produce a reactive $\mathrm{OH}$-radical and $\mathrm{H}^{+}$that delocalizes on the nearby water molecules (Eq. 4).

$T N T\left(h^{+}\right)+H_{2} O_{(T N T)} \rightarrow T N T+O H_{(T N T)}^{*}+H^{+}$
Table 2 Mean formation rate of products $\left(\bar{r}_{i}\right)$, methane conversion $\left(\mathrm{K}_{\mathrm{CH}_{4}}\right)$ and broadband apparent quantum yield values regarding to hydrogen formation $\left(\mathrm{Z}_{\mathrm{H}_{2}}\right)$, calculated from the results of different experiments

\begin{tabular}{lllllllll}
\hline Reactant & Catalyst & \multicolumn{2}{l}{$\bar{r}_{i}\left(\mu \mathrm{mol} \mathrm{h}{ }^{-1} \mathrm{~g}^{-1}\right)$} & & & $\mathrm{K}_{\mathrm{CH}_{4}}(\%)$ & $\mathrm{Z}_{\mathrm{H}_{2}}$ & $\begin{array}{c}\text { Average parti- } \\
\text { cle size (nm) }\end{array}$ \\
\cline { 3 - 7 } & & $\mathrm{CH}_{4}$ & $\mathrm{H}_{2}$ & $\mathrm{C}_{2} \mathrm{H}_{6}$ & $\mathrm{CH}_{3} \mathrm{OH}$ & & & \\
\hline $\mathrm{CH}_{4}$ & $\mathrm{TNT}$ & $-8.7^{\mathrm{b}}$ & $1.4^{\mathrm{b}}$ & $1.2^{\mathrm{b}}$ & b.d.1 & 0.2 & $1.1 \times 10^{-6}$ & - \\
& $\mathrm{Au} / \mathrm{TNT}$ & $-70^{\mathrm{a}}$ & $116^{\mathrm{a}}$ & $12^{\mathrm{b}}$ & $1.0^{\mathrm{b}}$ & 1.6 & $7.2 \times 10^{-5}$ & $3.1 \pm 0.9$ \\
& $\mathrm{Au} / \mathrm{TiO}_{2}$ & $-22^{\mathrm{a}}$ & $48^{\mathrm{a}}$ & $1.5^{\mathrm{b}}$ & $0.1^{\mathrm{c}}$ & 0.4 & $3.8 \times 10^{-5}$ & $8.6 \pm 1.5$ \\
\hline
\end{tabular}


The as-generated hydroxide radicals are very aggressive oxidants and start to oxidize methane in a radical-type reaction (Eq. 5). The formed methyl radical adsorbs on the metal surface.

$\mathrm{OH}_{(T N T)}^{*}+\mathrm{CH}_{4(g)} \stackrel{M}{\rightarrow} \mathrm{H}_{2} \mathrm{O}_{(T N T)}+\mathrm{CH}_{3(M)}^{*}$

We cannot exclude that methane also reacts directly with the holes resulting in methyl radicals on the titanate surface (Eq. 6).

$T N T\left(h^{+}\right)+\mathrm{CH}_{4(g)} \rightarrow T N T+\mathrm{CH}_{3(T N T)}^{*}+H^{+}$

The methyl radical decomposes consecutively to hydrogen and carbon or recombines to ethane.

$$
\begin{aligned}
& \mathrm{CH}_{3(M)}^{*} \stackrel{M}{\rightarrow} \mathrm{CH}_{2(M)}^{*}+H_{(M)}^{*} \rightarrow \rightarrow C_{(M)}+\frac{3}{2} H_{2(g)} \\
& 2 \mathrm{CH}_{3(M)}^{*} \stackrel{M}{\rightarrow} C_{2} H_{6(M)} \rightarrow C_{2} H_{6(g)}
\end{aligned}
$$

Nanoparticles of $\mathrm{Au}$ (and some other metals) are coupled to $\mathrm{TiO}_{2}$ (including titanate nanorods) to exploit localized surface plasmonic resonance (LSPR) in photocatalysis $[53,54]$. This phenomenon usually occurs in nanoparticles $(>3 \mathrm{~nm}$ ), and depends strongly on the particle size, shape and local dielectric environment. This effect is expected to be more pronounced in the case of $\mathrm{Au} / \mathrm{TiO}_{2}$ where the average particle size is bigger $(8.6 \pm 1.5 \mathrm{~nm})$ [54].

The other important observation is that TNT can stabilize gold in small sizes (below $3 \mathrm{~nm}$ ), and contain a significant amount of $\mathrm{Au}^{+}$in ion exchange position (Figs. 1, 2). In such small dimensions the plasmonic feature (LSPR) does not operate. However, multiple molecular-like transitions of the gold cluster $\left(\mathrm{Au}_{25}\right)$ were observed by UV-Vis spectroscopy (Fig. 7) and $\mathrm{Au}^{+}$was detected by XPS. As discussed above, the small metal clusters $\left(\mathrm{Au}_{25}\right.$, probably with a partial positive charge), can bind strongly to the defect sites in TNT. These clusters may be directly involved in the photo-induced reactions, namely in the direct activation of the methane $/ \mathrm{Au}_{25}{ }^{\delta+}$ complex during irradiation. We strongly suggest that $\mathrm{Au}^{+}$ions may have a similar ability.

$\mathrm{CH}_{4} / \mathrm{Au}_{2} 5 \stackrel{h v}{\rightarrow} \mathrm{CH}_{3}^{*}+\mathrm{H}^{+}$

In the photo-induced transformation of methane on $\mathrm{Au} / \mathrm{TNT}, \mathrm{CH}_{3} \mathrm{OH}$ was also produced [48]. Its amount was one order of magnitude higher than on $\mathrm{Au} / \mathrm{TiO}_{2}$. After $1 \mathrm{~h} \mathrm{UV}$ irradiation, the collected DRIFT spectra indicated that bidentate carbonate and monodentate formate were formed at $1585-1558 \mathrm{~cm}^{-1}$ [48]. The further reduction of formate can be photo-assisted. The $\mathrm{Au}^{+}$coordinated to the formate facilitates the transformation to methoxide, which then gives methanol:

$\mathrm{HCOO}^{*} / \mathrm{Au}^{+1}+2 \mathrm{H}_{2} \stackrel{h v}{\rightarrow} \mathrm{CH}_{3} \mathrm{O}+\mathrm{H}_{2} \rightarrow \mathrm{CH}_{3} \mathrm{OH}_{(g)}$

\subsection{Photocatalytic Reaction of $\mathrm{CO}_{2}+\mathrm{H}_{2}$ on Au/TNT}

Carbon dioxide chemistry has attracted increased interest recently, motivated by environmental concerns (greenhouse effect, global warming) and by the desirable utilization of $\mathrm{CO}_{2}$ as a feedstock for the chemical industry $[55,56]$. The chemical activation of $\mathrm{CO}_{2}$ is a rather popular buzzword nowadays in catalysis and surface science when discussing $\mathrm{CO}_{2}$ chemistry. It involves the activation and cleavage of the strong carbon-oxygen bonds and a subsequent establishment of new chemistry with higher enthalpy [57-59]. Once the surprisingly high catalytic activity of nanosized Au has been discovered in many reactions, its influence on the catalytic chemistry of $\mathrm{CO}_{2}$ has also been tested $[8,48,60,61]$. Here we focus on comparing the thermal and the photo-induced $\mathrm{CO}_{2}+\mathrm{H}_{2}$ reactions on titanate-supported Au catalysts.

In our recent study we demonstrated that the size of gold nanoparticles on the surface has the most important effect on the final activity of the studied catalysts in the thermally activated $\mathrm{CO}_{2}+\mathrm{H}_{2}$ reaction [62]. The size of the $\mathrm{Au}$ nanoparticles was controlled by their preparation method (Table 1). The synthesis with $\mathrm{NaBH}_{4}$ generally resulted in smaller Au nanoparticles $(\leq 3 \mathrm{~nm})$ on both $\mathrm{Au} / \mathrm{TNT}$ and $\mathrm{Au} /$ $\mathrm{TiO}_{2}$ than the impregnation-post-reduction method, hence we can conclude that smaller nanoparticles are more active even if their total amount on the surface is less. In this size range $\mathrm{Au} / \mathrm{TNT}$ and $\mathrm{Au} / \mathrm{TiO}_{2}$ have the same activity in thermally induced $\mathrm{CO}_{2}$ hydrogenation. $\mathrm{CO}$ and $\mathrm{H}_{2} \mathrm{O}$ were the only products in the thermal reaction routes. Some typical conversion data are plotted in Fig. 8. The proposed mechanism of $\mathrm{CO}$ formation is the decomposition of the formate to $\mathrm{CO}$ and a surface $\mathrm{OH}$ group [62,63].

In the present work, we study the photocatalytic reaction of $\mathrm{CO}_{2}$ with $\mathrm{H}_{2}$ on titanate supported gold catalysts. The results reveal fundamental differences in the reaction schemes as the products of the two routes are $\mathrm{CO}$ (thermal process) and $\mathrm{CH}_{4}$ (photocatalytic route) indicating the importance of photogenerated electron-hole pairs in the reaction.

As we have already mentioned above, when synthesizing gold clusters, reduction with hydrogen at $473-573 \mathrm{~K}$ after impregnation (method A) usually results in higher inhomogeneity: the average size in the present case is $9.4 \pm 2.9 \mathrm{~nm}$ on TNT. On the other hand, when reducing with $\mathrm{NaBH}_{4}$ (method B) the size distribution is narrower, with the average size being $3.6 \pm 1.4 \mathrm{~nm}$ for TNT (Table 3 ). We could produce small gold clusters $(3.9 \pm 1.5 \mathrm{~nm})$ on $\mathrm{TiO}_{2}$ as well 


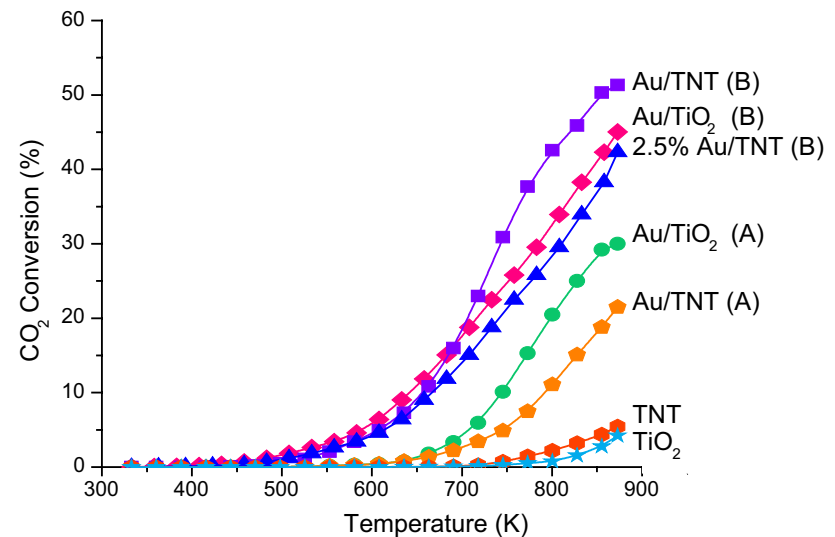

Fig. 8 The conversion of $\mathrm{CO}_{2}$ on different catalysts in the $\mathrm{CO}_{2}+\mathrm{H}_{2}$ reaction as a function of temperature. a Indicates reduction with $\mathrm{H}_{2}$, b Denotes preparation using $\mathrm{NaBH}_{4}$. The gold particle sizes are listed in Table 1

by reducing with $\mathrm{NaBH}_{4}$ (method B). As presented in Table 3, Au/TNT at same gold size exhibits significantly higher photoactivity than $\mathrm{Au} / \mathrm{TiO}_{2}$. The average formation rate of $\mathrm{CH}_{4}$ was $\sim 2.5$ times higher on Au/TNT(B). This means that the smaller size gold particles, which are characteristic of method B, cannot be the only reason for the outstanding activity. We believe that the high ion-exchange ability of the TNT plays an important role in the enhancement of its activity. It is also important to emphasize that the concentration of $\mathrm{Au}^{+}$in ion exchange position is higher after reduction with $\mathrm{NaBH}_{4}$ (method B) as can be seen in Fig. 5 .

The fundamental difference with respect to the thermally induced reaction is that exclusively methane formation was observed. A typical methane formation process is displayed in Fig. 9. The formation of methane is restricted to the UV irradiation periods. We should emphasize that methane was not detected when $\mathrm{CO}_{2}$ was not present during irradiation. Figure 8 illustrates fitting Eq. 12 to the primary data. The formation rates and fitted parameters are shown in Table 3.

Momentary formation rates $\left(r_{i}(t)\right)$ were calculated in $\mu \mathrm{mol}$ $\mathrm{h}^{-1} \mathrm{~g}^{-1}$ units. Average formation rates for a $9 \mathrm{~h}$ irradiation period were calculated for the main product with the integration of the experimental data:

$\bar{r}_{i}=\frac{1}{9 h} \int_{0}^{18 h} r_{i}(t) d t$

The formation rates generally decrease over time. The decrease has an exponential first and a linear second part. We fitted the following function to the experimental data to determine the initial rate and the parameters that characterize the rate of activity decrease:

$r_{i}(t)=A e^{-\frac{t}{\tau}}+B t+C$

Here $A, B, C$ and $\tau$ are the fitting parameters, $\tau$ is the time-constant of the exponential decrease, and $B$ is the slope of the linear part. The initial formation rate was calculated using the following equation:

$r_{i, 0} \equiv r_{i}(0)=A+C$

The exchanged gold ions can introduce surplus energy levels in the band structure of the TNT and trap photo-generated electrons, hence elongating the lifetime of electron-hole pairs. On the other hand, $\mathrm{Au}^{+}$ions as surface active sites can ease $\mathrm{CO}_{2}$ reduction by coordinating the electron rich parts of the intermediate products similarly as oxygen vacancies do. Nevertheless, the reaction also proceeds without the mediation of gold cations, as it can be seen in Table 3. We propose that the gold cations exert a promoting effect here.

Photocatalytic experiments performed in the DRIFTS sample holder did not result in any new peaks attributed to the irradiation. The same bands appeared upon the adsorption of reactants as in the thermal experiments and these absorptions did not change due to irradiation (Fig. 10a). For comparison, the DRIFTS results obtained on $\mathrm{Au} /$ $\mathrm{TiO}_{2}$ (B) as can be also seen in Fig. 10b. On Au/TNT (B) bidentate carbonates $\left(1572,1383 \mathrm{~cm}^{-1}\right)$ [64], bicarbonates $\left(1632,1437,1222 \mathrm{~cm}^{-1}\right)[64]$ and formates $\left(\nu_{\mathrm{a}}(\mathrm{OCO})\right.$ at 1501 , and $\nu_{\mathrm{s}}(\mathrm{OCO})$ at $\left.1312 \mathrm{~cm}^{-1}\right)$ [65-67] are formed (Fig. 10A). Carboxylate species that are more general for
Table 3 Rates and parameters concerning methane formation

\begin{tabular}{llllll}
\hline Catalyst & $\begin{array}{l}\bar{r}\left(\mu \mathrm{mol} \mathrm{h}^{-1} \mathrm{~g}^{-1}\right) \\
\text { err: } \pm 20 \%\end{array}$ & $\begin{array}{l}r_{0}\left(\mu \mathrm{mol} \mathrm{h} \mathrm{h}^{-1} \mathrm{~g}^{-1}\right) \\
\text { err: } \pm 12 \%\end{array}$ & $\tau(\mathrm{h})$ & $\left.B(\mu \mathrm{mol} \mathrm{g})^{-1}\right)$ & $\begin{array}{l}\text { Mean gold } \\
\text { particle diameter } \\
(\mathrm{nm})\end{array}$ \\
\hline $\mathrm{TNT}$ & 0.12 & 0.59 & 1.14 & -0.015 & - \\
$\mathrm{Au} / \mathrm{TNT}(\mathrm{A})$ & 0.23 & 0.93 & 0.83 & -0.009 & $9.4 \pm 2.9$ \\
$\mathrm{Au} / \mathrm{TiO}_{2}(\mathrm{~B})$ & 0.17 & 0.82 & 0.68 & -0.008 & $3.9 \pm 1.5$ \\
$\mathrm{Au} / \mathrm{TNT}(\mathrm{B})^{\mathrm{a}}$ & 0.49 & 2.41 & 0.93 & -0.020 & $3.6 \pm 1.4$ \\
\hline
\end{tabular}

$\bar{r}$, average formation rate, $r_{0}$, initial formation rate, $\tau$, time constant of the exponential decay, $B$, linear rate loss parameter

${ }^{\mathrm{a}}$ The results of five measurements are averaged 


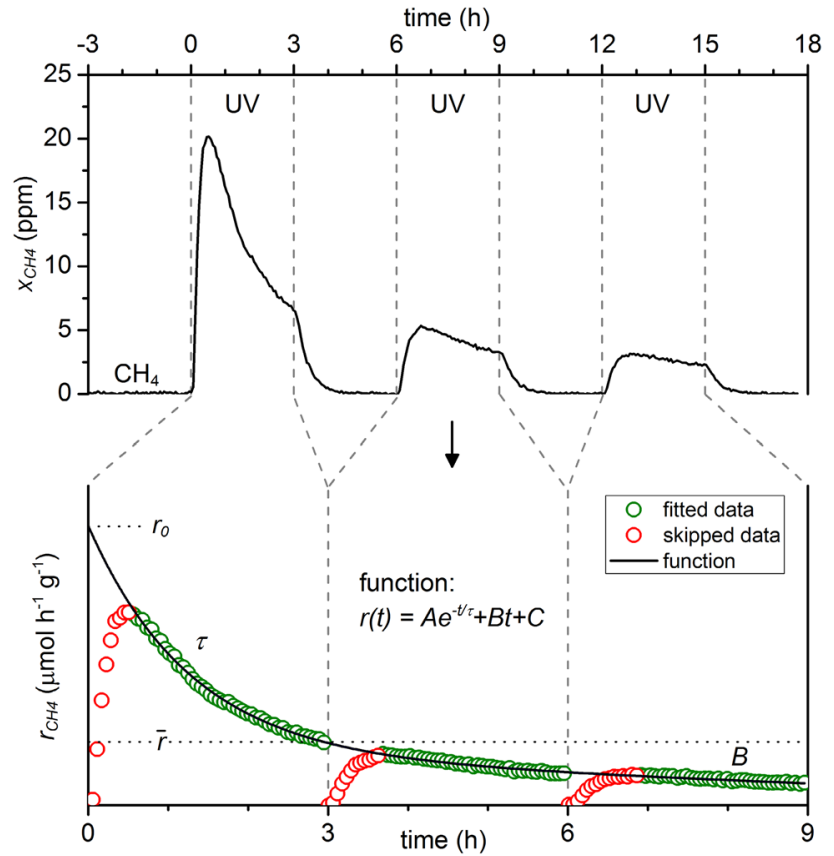

Fig. 9 An example of the evaluation of photocatalytic measurement data

$\mathrm{TiO}_{2}$ were not observed. The features of bicarbonate (1636, $\left.1453,1222 \mathrm{~cm}^{-1}\right)$, carboxylate $\left(1671,1245 \mathrm{~cm}^{-1}\right)$, bidentate carbonate $\left(1570,1405 \mathrm{~cm}^{-1}\right)$ and formate $\left(\nu_{\mathrm{a}}(\mathrm{OCO})\right.$ at $1511 \mathrm{~cm}^{-1}$ and $\nu_{\mathrm{s}}(\mathrm{OCO})$ at $\left.1347 \mathrm{~cm}^{-1}\right)$ can be observed at room temperature on $\mathrm{Au} / \mathrm{TiO}_{2}$ (B). During the thermal reaction, there was no indication of the formation of oxygenated hydrocarbons. The loss of crystallographic water is indicated by the negative peak at $1632 \mathrm{~cm}^{-1}$. Formates appearing on $\mathrm{Au} / \mathrm{TiO}_{2}(\mathrm{~B})$ and on $\mathrm{Au} / \mathrm{TNT}(\mathrm{B})$ samples must be important intermediate products in $\mathrm{CO}_{2}$ hydrogenation. It is remarkable that the bands of the formate species, especially the $\nu_{\mathrm{s}}(\mathrm{OCO})$ mode, appeared at higher wavenumbers in the case of $\mathrm{Au} / \mathrm{TiO}_{2}$ (B) than on $\mathrm{Au} / \mathrm{TNT}$ (B) (Fig. 10). This could be due to the coordinating effect of $\mathrm{Au}^{+}$or $\mathrm{Au}^{\mathrm{n}+}$ that weakens the $\mathrm{C}=\mathrm{O}$ bonds.

We hypothesize that the photocatalytic reduction of $\mathrm{CO}_{2}$ takes place through surface formates. The first step is the activation of $\mathrm{CO}_{2}$, in which a radical anion $\left(\mathrm{CO}_{2}{ }^{*-}\right)$ is formed [57, 58, 61]. Carboxylate radicals arise from $\mathrm{Ti}^{3+}$ $\left(=e_{\left(T i^{4+}\right)}^{-}\right)$sites (Eq. 14). Surface formates form from carboxylate radical anions according to Eq. 15 .

$$
\begin{aligned}
& \mathrm{CO}_{2(g)}+e_{\left(T i^{4+}\right)}^{-} \rightarrow \mathrm{CO}_{2\left(T i^{4+}\right)}^{*-} \leftrightarrow \mathrm{CO}_{2\left(T i^{3+}\right)}^{*} \\
& \mathrm{CO}_{2\left(T i^{4+}\right)}^{*-}+H_{(T N T)}^{+}+e^{-} \rightarrow \mathrm{HCOO}_{\left(T i^{4+}\right)}^{-}
\end{aligned}
$$

On the other hand, UV irradiation can also generate $e_{\left(T i^{4+}\right)}^{-}$ electrons, which results in the formation of carboxylates in the presence of $\mathrm{CO}_{2}[48,68]$.

$$
H_{2}+O_{(T N T)} \rightarrow H_{2} O_{(T N T)} \rightarrow H_{2} O_{(g)}+\square_{(T N T)}^{2+}+2 e_{\left(T i^{4+}\right)}^{-}
$$

Additionally, the gold-support interface forms a rectifying Schottky contact that helps in separating charge carriers,
Fig. 10 Infrared spectra recorded during the $\mathrm{CO}_{2}+\mathrm{H}_{2}$ thermal reaction on different catalysts: a Au/TNT; b Au/TiO
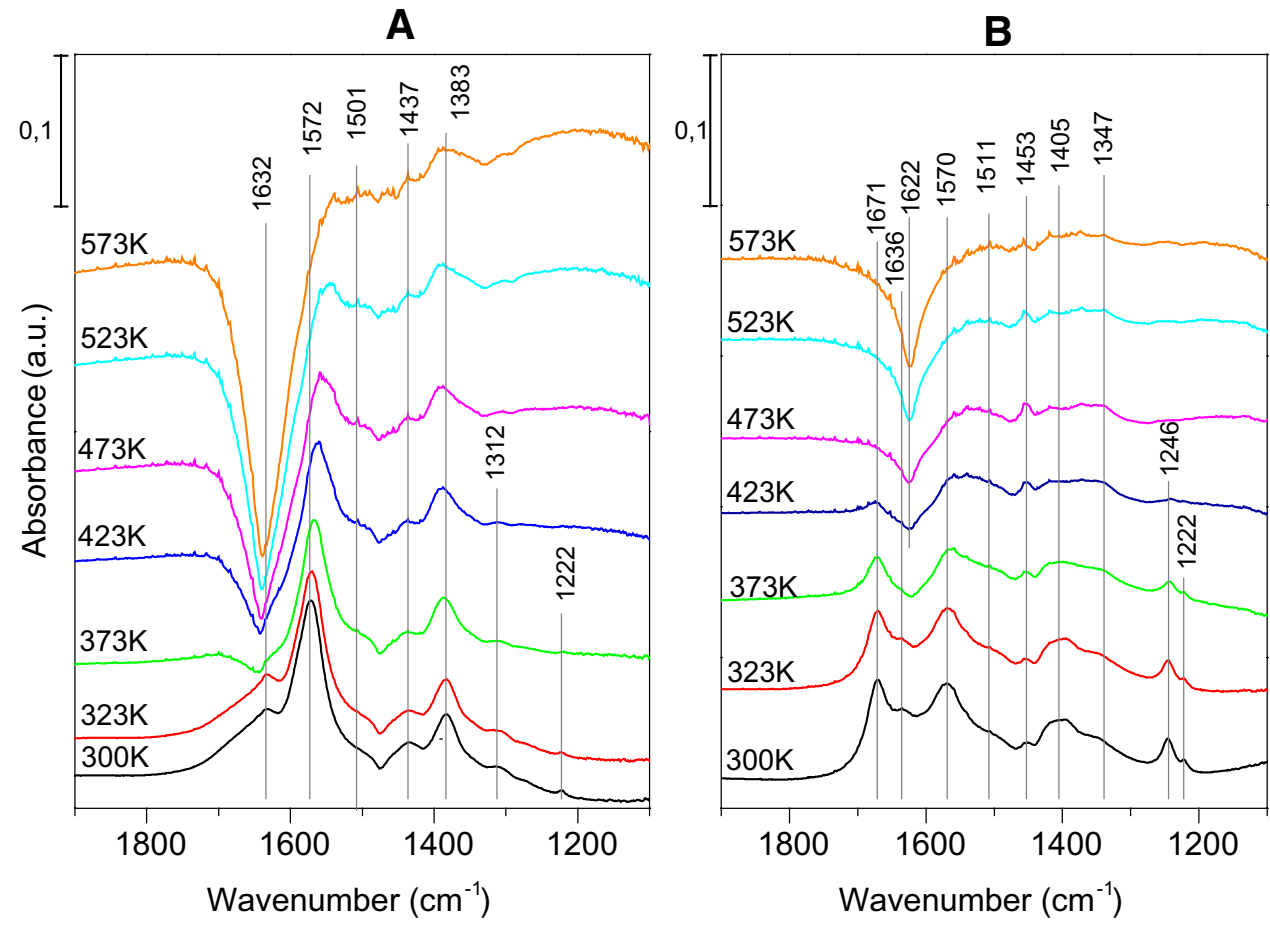
thus improving the utilization of electrons and holes in the reaction. The further reduction of formate has to be photoassisted. We summarize the reaction steps in Scheme 1. In these reaction steps we emphasize the importance of the gold cation. The gold cation coordinates the formate and facilitates the weakening of the $\mathrm{C}=\mathrm{O}$ bond. A further photo-generated hole and a $\mathrm{H}_{2}$ molecule constitute enough activation for the reduction. The formed surface species are unstable and undergo further reduction. Finally, methane forms through a short lifetime methoxy intermediate. All intermediates after formate can be assumed to have really short lifetimes, since they were not detected using infrared spectroscopy. Even so the reduction of surface methoxy species can also be photo-assisted just as the activation of the formate works.

Without continuous UV-irradiation in a thermally activated reaction, the formate species reacts further at higher temperatures yielding $\mathrm{CO}$ and water:

$\mathrm{HCOO}_{\left(T^{4+}\right)}^{-}+\mathrm{H}_{(T N T)}^{+} \rightarrow \mathrm{CO}_{(\mathrm{Au})}+\mathrm{H}_{2} \mathrm{O}_{\left(T i^{4+}\right)}$

A further possible mechanism of the $\mathrm{CO}$ formation is the decomposition of the surface formate to $\mathrm{CO}$ and a surface $\mathrm{OH}$ group (Eq. 18) [62, 68].

$$
\mathrm{HCOO}_{\left(T^{4+}\right)}^{-} \rightarrow \mathrm{CO}_{(\mathrm{Au})}+\mathrm{OH}_{\left(\mathrm{Ti}^{4+}\right)}^{-}
$$

Theoretically, the further reduction of $\mathrm{CO}$ to $\mathrm{H}_{2} \mathrm{CO}$ would also be possible with the help of oxygen vacancies, but the probability of $\mathrm{CO}$ desorption is high enough to stop the process at the $\mathrm{CO}$ stage due to the elevated temperature (403 K):

$C O_{(A u)} \stackrel{q}{\rightarrow} C O_{(g)}$

In contrast to the thermally mediated reaction where the reaction pathway was different $\left(\mathrm{CO}+\mathrm{H}_{2} \mathrm{O}\right.$ formation), in photo-induced $\mathrm{CO}_{2}$ hydrogenation a strong activity change was detected. We suggest that the main reason behind the observed deactivation is the accumulation of surface intermediates and side products as bidentate carbonates, bicarbonates and carbon formed from reactants at the irradiation temperature (348 K).

\section{Concluding Remarks}

In conclusion, recent literature data indicates that sub-nanosized gold clusters $\left(\mathrm{Au}_{8}\right)$ on $\mathrm{MgO}$ and $\mathrm{Au}_{25}$ on $\mathrm{CeO}_{2}$ rods can be prepared and characterized. Both clusters exhibited high catalytic activity in $\mathrm{CO}$ combustion at low temperatures. $\mathrm{Au}_{9} / \mathrm{TiO}_{2}$ was also produced and characterized. $\mathrm{Au}_{38} /$ $\mathrm{TiO}_{2}$ showed the expected Arrhenius behavior, with apparent activation energy of $31.2 \mathrm{~kJ} / \mathrm{mol}$ for the $\mathrm{CO}+\mathrm{O}_{2}$ reaction. However, the turnover frequency was lower than that over catalysts prepared by conventional methods on the same titania.

TNT have numerous advantageous properties that play important roles in several catalytic reactions. Titanate nanostructures are of great interest for catalytic applications because their high surface area and cation exchange capacity make a high metal dispersion possible. Ion exchange allows titanate nanostructures to incorporate metal adatoms in their framework, which may create another type of active center besides metal clusters. Similar to $\mathrm{CeO}_{2}$ rods, TNT can also stabilize sub-nanosized gold clusters in $\mathrm{Au}_{25}$ form.

$\mathrm{Au} / \mathrm{TNT}$ decorated with sub-nanosized gold clusters exhibited the highest photocatalytic activity in methane transformation. The main product of this photo-induced process is hydrogen. Small metal clusters $\left(\mathrm{Au}_{25}\right.$, probably with a partial positive charge) can bind strongly to defect sites in TNT. These clusters may be directly involved in photo-induced reactions, namely in the direct activation of
Scheme 1 The proposed mechanism of the photocatalytic transformation of formates on the surface of the Au/TNT (B) catalyst. The gold cation facilitates the weakening of the $\mathrm{C}=\mathrm{O}$ bond
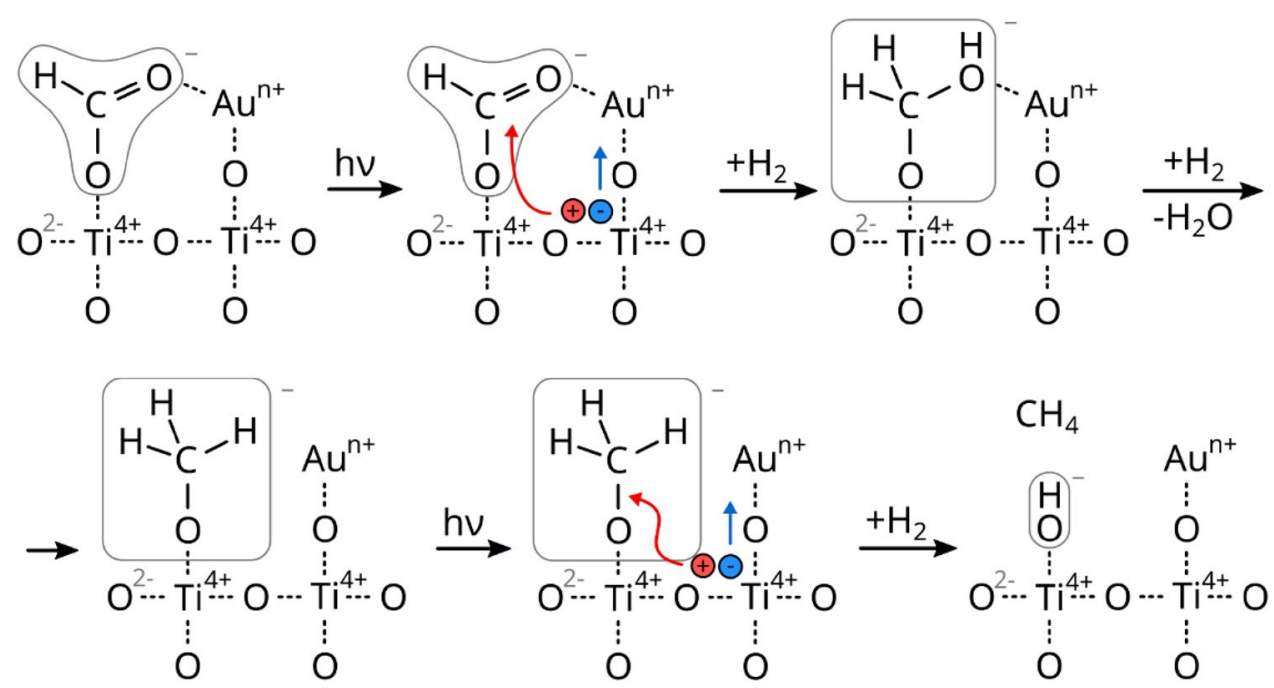
the methane- $\mathrm{Au}_{25}$ complex during irradiation. The molecular-like clusters $\left(\mathrm{Au}_{25}\right)$ may form complexes with the reactants in which the electron transfer directly occurs during UV irradiation.

Our results revealed fundamental differences in the reaction schemes as the products of the two routes are $\mathrm{CO}$ (thermal process) and $\mathrm{CH}_{4}$ (photocatalytic route) indicating the importance of photo-generated electron-hole pairs in the reaction. The presence of gold nanoparticles on the surface has been found to have multiple roles. On the one hand, the metal promotes the adsorption and scission of reactants, important for both types of reactions. On the other hand, the gold-support interface forms a rectifying Schottky contact that helps in the separation of photogenerated carriers, thus improving the utilization of electrons and holes in the reduction and oxidation steps, respectively. Furthermore, gold ions in the cationic sites of the titanate lattice promote the photocatalytic transformation of formate (which is one of the intermediates), thus advancing the reaction further towards the fully reduced product.

For the sake of completeness we should mention that small, even sub-nanosized, clusters can be prepared on nonoxide type supports as well. The graphene structure is a good candidate for size selective metal deposition [69-71]. Very small Au clusters can also be prepared on hexagonal boron nitride $[72,73]$. It was demonstrated that for these small clusters $\left(\mathrm{Au}_{\mathrm{n}},(\mathrm{n}=2-4)\right.$ on $\mathrm{h}-\mathrm{BN} / \mathrm{Rh}(111)$ nanomesh $)$ a linear geometry is the most stable. All atoms in these clusters are negatively charged and might be catalytically active [74]. Porphyrin-related macrocycles are also able to stabilize different atoms or ions on the surface. Their surface can modified with co-deposited metal atoms, substrate metal atoms and oxide lattice ions $[75,76]$. Their catalytic application is well-documented in a recent review [77].

Acknowledgements Open access funding provided by University of Szeged (SZTE). The authors wish to thank Mr. Balázs László and Mrs Kornelia Baán for executing the photocatalytic and infrared measurements and also Prof. András Erdőhelyi for fruitful discussions. Financial support of this work by the National Research Development and Innovation Office through Grants GINOP-2.3.2-15-2016-00013 and NKFIH OTKA K120115 (Z.K.) and K126065 (A.K.) is gratefully acknowledged.

Open Access This article is distributed under the terms of the Creative Commons Attribution 4.0 International License (http://creativeco mmons.org/licenses/by/4.0/), which permits unrestricted use, distribution, and reproduction in any medium, provided you give appropriate credit to the original author(s) and the source, provide a link to the Creative Commons license, and indicate if changes were made.

\section{References}

1. Sault AG, Madix RJ, Campbell CT (1986) Surf Sci 169:347-356
2. Hammer B, Norskov JK (1995) Nature 376:238-240

3. Bus E, Müller JT, van Bokhoven JA (2005) J Phys Chem B 109:14581-14587

4. Mavrikakis M, Stolze P, Norskov JK (2000) Catal Lett 64:101-106

5. Haruta M (1997) Catal Today 36:153-166

6. Huber H, Mcintosh D, Ozin GA (1997) Inorg Chem 16:975-979

7. Bamwenda GR, Tsubota S, Nakamura T, Haruta M (1997) Catal Lett 44:83-87

8. Lin SD, Bollinger M, Vanice MA (1993) Catal Lett 17:245-262

9. Boccuzzi F, Cerrato G, Pinna F, Strukul G (1998) J Phys Chem B 102:5733-5736

10. Valden M, Lai X, Goodman DW (1998) Science 281:1647-1650

11. Freund H-J, Nilius N, Risse T, Schauermann S (2014) Phys Chem Chem Phys 16:8148-8167

12. Shaikhutdinov S, Freund H-J (2012) Annu Rev Phys Chem 63:619-633

13. James TE, Hemmingson J, Campbell SL C. T (2015) ACS Catal 5:5673-5678

14. Liu L, Corma A (2018) Chem Rev 118:4981-5079

15. Taylor K, Pettiette-Hall CL, Cheshnowsky O, Smalley RE (1992) J Chem Phys 96:3319-3329

16. Boronat M, Leyva-Perez A, Corma A (2014) Acc Chem Res 47:834-844

17. Wang J, Wang G, Zhao J (2002) Phys Rev B 66:035418

18. Tian Y, Tatsuma T (2004) J Am Chem Soc 127:7632-7637

19. Ismail AA, Bahnemann DW, Bannat I, Wark M (2009) J Phys Chem C 113:5417-5421

20. Park H, Park Y, Kim W, Choi W (2013) J. Photochem. Photobiol. C 15:1-20

21. Kowalska E, Mahaney OOP, Abe R, Ohtani B (2010) Phys Chem Chem Phys 12:2344-2355

22. Subramanian V, Wolf EE, Kamat PV (2004) J Am Chem Soc 126:4943-4950

23. Somorjai GA, Park JY (2008) Top Catal 49:126-135

24. Freund H-J (2016) J Am Chem Soc 138:8985-8996

25. Park JY, Lee SW, Lee C, Lee H (2017) Catal Lett 147:1851-1860

26. Lee J, Shim HS, Lee M, Song JK, Lee D (2011) J Phys Chem Lett 2:2840-2845

27. Fu Q, Wagner (2007) Surf Sci Rep 62:431-498

28. Li H, Li L, Li Y (2013) Nanotechnol Rev 2:515-528

29. Schmid G (2008) Chem Soc Rev 37:1909-1930

30. Hassan S, Qahtani A, Kimoto K, Bennett T, Alvio JF, Andersson GG, Metha GF, Golovko VB, Sasaki T, Nakayama T (2016) J Chem Phys 144:114703--

31. Yulikov M, Sterrer M, Heyde M, Rust H-P, Freund H-J (2006) Phys Rev Lett 96:146804

32. Sanchez A, Abbet S, Heiz U, Schneider WD, Hakkinen H, Barnett RN, Landman U (1999) J Phys Chem A 103:9573-9578

33. Yoo B, Häkkinen H, Landaman U, Wörz A, Antonietti J-M, Abbet S, Judai K, Heiz U (2005) Science 307:403-407

34. Häkkinen H, Abbet S, Sanchez A, Heiz U, Landman U (2003) Angew Chem Int Ed Engl 42:1297-1300

35. Zheng N, Stucky GD (2006) J Am Chem Soc 128:14278-14280

36. Nie X, Qian H, Ge Q, Xu H, Jin R (2012) ACS Nano 6:6014-

37. Nie X, Zeng C, Ma X, Qian H, Ge Q, Xu H, Jin R (2013) Nanoscale 5:5912-5918

38. Gaur S, Miller JT, Stellwagen D, Sanampudi A, Kumar CSSR, Spivay JJ (2012) Phys Chem Chem Phys 14:1627-1634

39. Rosi NL, Giljohann DA, Thaxton CS, Lytton-Jean AKR, Han MS, Mirkin C (2006) Science 312A:1027-1030

40. Wohltjen H, Snow AW (1998) Anal Chem 70:2856-2859

41. Heaven MW, Dass A, White PS, Holt PS, Murray RW (2008) J Am Chem Soc 130:3754-3755

42. Zhu M, Aikens CM, Frederick J, Hollander J, Schatz GC, Jin R (2008) J Am Chem Soc 130:5883-5885 
43. Wu Z, Jiang D, Mann AKP, Mullins DR, Qiao Z, Allard LF, Zeng C, Jin R, Overbury SH (2014) J Am Chem Soc 136:6111-6122

44. Kasuga T, Hiramatsu M, Hoson A, Sekino T, Niihara K (1998) Langmuir 14:3160-3163

45. Kukovecz Á, Kordás K, Kiss J, Kónya Z (2016) Surf Sci Rep 71:473-546

46. Sun X, Li Y (2003) Chem Eur J 9:229-2238

47. Pusztai P, Puskás R, Varga E, Erdőhelyi A, Kukovecz Á, Kónya Z, Kiss J (2014) Phys Chem Chem Phys 16:26786-26797

48. László B, Baán K, Varga E, Oszkó A, Erdőhelyi A, Kónya Z, Kiss J (2016) Appl Catal B 199:473-484

49. Kukovecz A, Pótári G, Oszkó A, Kónya Z, Erdőhelyi A, Kiss J (2011) Surf Sci 605:1048-1055

50. Kiss J, Pusztai P, Óvári L, Baán K, Merza G, Erdőhelyi A, Kukovecz Á, Kónya Z (2014) e-J Surf Sci Nanotechnol 12:252-258

51. László B, Baán K, Oszkó EA, Kiss J, Kónya Z (2018) Top Catal 61:875:888

52. Kiss J, Németh R, Koós Á, Raskó J (2008) J Nanosci Nanotechnol 9:3828-3836

53. Tian Y, Tatsuma T (2005) J Am Chem Soc 127:7632-7637

54. Dosado AG, Chen W-T, Chan A, Sun-Waterhouse D, Waterhouse GIN (2015) J Catal 330:238-254

55. Burghaus U (2014) Prog Surf Sci 89:161-217

56. Narayanan H, Viswanathan B, Yesodharan S (2016) Curr Catal 5:79-107

57. Freund HJ, Roberts MR (1996) Surf Sci Rep 25:225-273

58. Solymosi F (1991) J Mol Catal 65:337-358

59. Ola O, Maroto-Valer MM (2015) J Photochem Photobiol C 24:16-42

60. Tóth M, Kiss J, Oszkó A, Pótári G, László B, Erdőhelyi A (2012) Top Catal 55:747-756

61. Halasi G, Gazsi A, Bánsági T, Solymosi F (2015) Appl Catal A 506:85-90

62. László B, Baán K, Ferencz ZS, Galbács G, Oszkó A, Kónya Z, Kiss J, Erdőhelyi A (2018) J Nanosci Nanotechnol 19:470-477

\section{Affiliations}

\section{János Kiss ${ }^{1}$ · Ákos Kukovecz ${ }^{2,3} \cdot$ Zoltán Kónya $^{1,2,3}$}

Zoltán Kónya

konya@ chem.u-szeged.hu

1 MTA-SZTE Reaction Kinetics and Surface Chemistry Research Group, University of Szeged, Szeged, Hungary
63. Halasi G, Schubert G, Solymosi F (2012) J Phys Chem C 116:15396-15405

64. Baltrusaitis J, Scuttlefield ZE, Grassian VH (2011) Chem Eng J 170:471-481

65. Collins SE, Baltanás ME, Bonivardi A. L (2004) J Catal 226:410-421

66. Raskó J, Kecskés T, Kiss J (2004) J Catal 226:183-191

67. Mattson A, Österlund L (2017) Surf Sci 663:47-55

68. Sarkar A, Gracia-Espino E, Wågberg T, Shchukarev A, Mohl M, Rautio AR, Pitkänen O, Sharifi T, Kordas K, Mikkola JP (2016) Nano Res 9:1956-1968

69. Sicot M, Leicht P, Zusan A, Bouvron S, Zander O, Weser M, Dedkov Y. Horn S, Fonin K M (2012) ACS Nano 6:151-158

70. Gotterbarm K, Späth F, Bauer U, Bronnbauer C, Steinrück H-P, Papp C (2015) ACS Catal 5:2397-2403

71. Papp C (2017) Catal Lett 147:2-19

72. Patterson MC, Habenicht BF, Kurrtz RL, Liu L, Xu Y, Sprunger PT (2014) Phys Rev B 89:205423

73. Gubó R, Vári G, Kiss J, Farkas AP, Óvári L, Berkó A, Kónya Z (2018) Phys Chem Chem Phys 20:15473-15485

74. Koch HP, Laskowski R, Blaha P, Schwarz K (2012) Phys Rev B $86: 155404$

75. Hatakeyama Y, Takahashi S, Nishikawa K (2010) J Chem Phys C 114:11098-11102

76. Franke M, Marchini F, Jux N, Steinrück H-P, Lytken O, Williams FJ (2016) Chem Eur 22:8520-8524

77. Gottfried JM (2015) Surf Sci Rep 70:259-379

Publisher's Note Springer Nature remains neutral with regard to jurisdictional claims in published maps and institutional affiliations. Department of Applied and Environmental Chemistry, University of Szeged, 6720 Szeged, Hungary

3 Interdisciplinary Excellence Centre, University of Szeged, Rerrich Béla tér 1, Szeged, Hungary 